\title{
The Application Strategy of Schema Theory in College English Reading Teaching
}

\section{Luo Yafeng}

Weinan Normal University, School of Foreign Studies, Weinan, Shaanxi, 714000

\author{
Keywords: College English, Reading Teaching, Schema Theory, Application Strategy
}

\begin{abstract}
Reading ability in College English is an important part of English teaching. It can help students accumulate vocabulary, acquire information and promote English listening, speaking and writing effectively. The goal of College English reading teaching is to improve the students' ability to acquire and deal with information and to analyze and solve problems. With the continuous deepening of the reform of education, the new curriculum standards have put forward higher requirements for College English Teaching in reading. Therefore, in the teaching of college reading, we should make full use of Schema Theory and make use of the systematic, dynamic and networking characteristics of schema process to improve students' understanding ability. In this paper, we should clarify the related concepts of schema theory, systematically analyze the problems in current college reading teaching, and apply schema theory to college reading teaching.
\end{abstract}

\section{Introduction}

Schema theory emphasizes reading is a changing dynamic process, a relatively active thinking activity, and plays a very important role in English reading. There are many advantages of schema, such as repetition of sources, rich levels, and interconnections between schemata. The reader can conjecture the content of the article according to the schema knowledge he acquired, and then discuss and modify it in the process of reading [1-2]. Under the guidance of schema theory, reading teaching can effectively promote the fast interaction between reading and schemas, maintain the activity and positive thinking state of brain knowledge network system, so as to achieve effective understanding of articles.

\section{An Overview of Schema Theory}

"Schema" was first proposed by Platon. He advocated that "idea" is what the eye of the mind can see. It is the existence of human reason and external reason. In 1804, the German philosopher Kant put forward the concept of schema explicitly, and defined it as "schema is the product of transcendental imagination. Transcendental time stipulation is the third concept that integrates intelligence and perceptual experience, communicating concepts and objects. Then the British psychologist Bartlett introduced the schema into the field of psychology. He thought that the core feature of schema is the active organization and feedback of past experience [3]. With the in-depth study of schema and schema theory, the linguists based on Cook believe that schema is the world in the long-term memory of the human brain. Although there are many definitions of schema, the meaning is similar. That is, schema is the basic framework for information understanding, which is widely applied to various scenarios. It is the cornerstone of cognition, and it can effectively promote people's cognition process and construction of external information.

The schema theory was put forward in 1960s, and the cognitive theory also reached a new height. Schema theory suggests that the role of known information in cognition is mainly used to explain the process of language acquisition closely related to cognition, and it is widely applied in reading. By Anderson et al as a representative of modern schema, they summarize and perfect further on the schema theory, and puts forward the schema does not represent a thing or event exists objectively, but structural knowledge units exist in the mind, which is representative of a structural network understanding of the world, have certain generality and universality [4]. 


\section{The Present Situation of College English Reading Teaching}

Reading is a complex psychological activity, with initiative and independence, and a process of thinking, filtering, processing and combining information based on its knowledge. As far as the current situation is concerned, the English reading ability of college students in China is not optimistic. The basic reason is that the students' reading ability is weak. The traditional English teaching mode in our country is dominated by teachers, and the students accept the learning passively [5]. As a result, students are generally lack of initiative and independent problem-solving ability. Especially in English reading teaching and learning, they usually expand vocabulary and explain grammar knowledge, but do not explore semantics in depth. Secondly, students do not have a real understanding of the reading materials during the long period of study. In reading class, there is no difference from other teaching methods. Even though reading comprehension effect assessment is limited to the interaction between teachers and individual students, the classroom discussion is a mere formality, resulting in the loss of students' reading motivation in class. Thirdly, in the process of College English learning, students' mother tongue learning has been completed, and their thinking is also mature, which has strong reading comprehension and logical judgement ability [6]. However, in the course of College English reading teaching, the emphasis on vocabulary and grammar in English teaching has never been attached to the cultural background. Therefore, when we teach English to college students, we cannot quickly extract relevant schema knowledge system, which affects the teaching effect of English reading and the comprehensive quality of students.

\section{The Significance of the Application of Schema Theory in the Teaching of College English Reading}

Reading comprehension is a process of cognition and communication in the world, and schema is the basis of the formation of reading mode. Reading is through the words, words, sentences to understand the article, and schema is through life experience to the core of the article accurate judgment. English reading teaching is a process of cognition and continuous learning. With the deepening of reading process, the reader's own knowledge system is also constantly strengthening and improving, so as to build a new knowledge background system [7]. In the process of building the new knowledge background system, teachers should actively guide students to read extensively, actively process information, fill gaps in knowledge, and lay a solid foundation for future reading.

Schema plays an expected role in reading comprehension, providing information for us to understand new things, such as readers in reading process, easier to understand familiar titles. Secondly, schema can adjust and supplement reading comprehension. Schema structure restricts readers' cognition and understanding to a certain extent, which can accurately and effectively deduce the "default value" of things. Thirdly, schema plays a role of editing. In the process of reading, it will automatically filter, edit and process input information, avoid excessive content and cause heavy burden on the brain [8]. Fourth, absorb the text and provide an ideal framework to facilitate the reader to quickly infer the problem or the hidden details. Fifth, the schema itself re combination, update the knowledge system, information on adsorption, combing and exposition, so as to improve the comprehensive ability to solve problems.

\section{The Basic Ideas of the Strategy Formulation of College English Reading Teaching under the Guidance of Schema Theory}

The strategy formulation of College English reading teaching should take full consideration of the students' cognitive level and choose appropriate strategies. According to the way of learning from simple to difficult, from shallow to deep strategy, we should choose easy learning strategies to mobilize students' interest in learning, and introduce difficult strategies to promote students' development. 


\subsection{Re-setting teaching goals}

In the process of College English reading teaching, teachers should pay attention to the expansion of background knowledge related to text. By reading and learning texts, students can enhance their understanding of geography, customs and culture. The goal of College English reading teaching is divided into two aspects, namely, language knowledge and comprehensive ability to use. Therefore, English reading teaching goal setting is divided into seven aspects, namely the vocabulary sentence, details of location information accurately, understand, grasp the author's intention, understand the text throughout the meaning, reflect the logical thinking ability, improve the amount of reading [9]. In addition, we should set up the corresponding macro goal, strengthen the ability of listening, speaking, reading and writing, and practice, through the knowledge of schema theory, stimulate students' interest in reading and set up good reading habits.

\subsection{Update teaching content in time}

The popularization of modern science and technology provides a variety of teaching methods for classroom teaching, and the curriculum is more rich and efficient. In order to improve students' reading comprehension and help students better understand their contents, College English teachers should pay attention to the coverage of teaching content, background knowledge and language knowledge in the process of reading teaching. Williams believes that language ability is the basis of reading ability [10]. Therefore, in the process of teaching English reading, teachers should design language knowledge according to the actual level of students, predict the obstacles that students may encounter and sweep them in advance. Schema theory emphasizes that readers need to have in-depth understanding of articles by means of life experience and social background, because these factors will have different effects on the article. Therefore, when the teacher is doing the content design, it is necessary to analyze the content of the article and make use of various teaching activities to provide the background support for the students. These background knowledge will also consolidate the original schema knowledge and lay a solid foundation for similar themes in the later period.

\subsection{Construction of teaching reflection mode}

In the teaching of English reading, schema theory is to realize the learners' understanding of the text effectively through continuous strengthening of the background knowledge. Therefore, the educational practice of "reflective mode" under the guidance of schema theory should be reconsidered in three directions: teaching materials, balanced reading theory, skills and evaluation. In the traditional teaching of English reading, teachers often reflect on the content and means of teaching and summarize them in time. But they often ignore the reflection on teaching material, whether the content of teaching material is reasonable, whether they can meet the teaching objectives and requirements of curriculum, all of which need to be deeply reconsidered. Secondly, there are differences between English reading teaching and traditional teaching methods under the guidance of schema theory, but there are also interlinked points [11]. How to balance the relationship between the two has become an important issue for College English teachers to reflect on. The last is the evaluation method, the traditional method of evaluation is also focused on the investigation of knowledge points, and does not evaluate the background structure and its thinking method. It is also a problem that educators need to reflect on to explore diversified evaluation methods to test students' reading ability.

\section{The Specific Strategies of Schema Theory Applied to College English Reading Teaching}

\subsection{Using schema to cultivate students' language ability}

The schema theory contains a variety of reading modes, which can effectively absorb information, enhance the ability of the affair, and effectively train the students' reading consciousness. Text is the communication medium between the author and the reader. Readers must fully contact the language information and background information in the text, so that we can fully 
understand the chill of the text and achieve the reading communicative ability. Therefore, in the process of College English teaching, we should start from the advantages of mother tongue, expand students' knowledge and enrich their knowledge of language and culture. In the process of English reading teaching, teachers should not only cultivate students' language abilities, but also increase students' vocabulary, help students understand sentences and meanings, improve reading speed and sort out text thinking.

\subsection{Using schema to expand students' reading}

Although the students have increased their vocabulary, they still can not fully understand the content of the article. This requires the cooperation of the background knowledge, so there is a close connection between the two. Only by understanding the cultural background knowledge in the text language can the language be handled correctly. To create a good language environment for students and to cultivate a good sense of language and way of thinking. For example, we subscribe to some English publications in the teaching, enrich the students' cultural background knowledge, and help students to understand the foreign culture [12]. Some students are proficient in English language, and have enough vocabulary. Due to lack of cultural background knowledge, they still can't read articles. Therefore, in the process of reading teaching, College English teachers should try to select topics that students are interested in, improve their interest in foreign cultures, mobilize their subjective initiative and take the initiative to understand foreign cultures.

\subsection{Fast activation schema strategy}

It is the core view of the schema theory that the learners think actively and actively in the process of reading. According to the investigation, it is found that in the course of College English reading teaching, the key to the accurate judgment and understanding of the reading text lies in the effective activation of the schema. As we all know, there are complex and diverse schemas stored in students' minds. However, college students are not aware of this in the process of reading, which requires teachers' guidance and using related strategies to quickly guide students to activate schemas in the brain. According to a large number of practice, there are three strategies to quickly activate schemata. One is targeted questioning; secondly, collective free discussion; third, training prediction ability.

\section{Conclusion}

Schema theory plays an important role in College English reading. In this paper, schema theory is systematically reviewed, and the advantages of Schema Theory in College English teaching are analyzed, focusing on the formation and application of Schema Theory in College English reading teaching. Therefore, in College English reading teaching, if we want to improve students' reading ability, we need not only to cultivate students' language abilities, but also to enrich their background knowledge and enrich their schema so as to improve their reading efficiency. In addition, teachers should use relevant strategies to activate the schemata already existing in the students' minds and improve the teaching efficiency.

\section{References}

[1] Zhang J. The Application of the Schema Theory in College English Listening Teaching[J]. Science \& Technology Vision, 2015.

[2] Ye M Z. Application of schema theory in college English reading course[J]. Journal of Jiamusi Vocational Institute, 2016.

[3] Liu H. An Empirical Study of College English Reading Teaching Based on Schema Theory[J]. Journal of Inner Mongolia Normal University, 2017.

[4] Zhang Y. The Application of Schema Theory to EFL Reading Teaching[C]// International Conference on Education Technology, Management and Humanities Science. 2016. 
[5] Wang F. A Brief Discussion about the Application of Schema Theory in the Teaching of College English Grammar[J]. Journal of Hetao College, 2015.

[6] Li M. Application of Schema Theory in Teaching English Reading in Vocational College[J]. Journal of Wuhan Engineering Institute, 2017.

[7] Liu B. Strategies of English listening teaching in higher vocational colleges under the guidance of schema theory[J]. Journal of Hunan Post \& Telecommunication College, 2016.

[8] Zhu L. Application of Schema Theory in Teaching of Vocational English Reading[J]. Journal of Chengdu Aeronautic Polytechnic, 2015, 6(1):59-65.

[9] Zhang F. The Application of Schema Theory in College English Reading Teaching[J]. Continuing Medical Education, 2014.

[10] Miao H E. Analysis of the Application of Schema Theory to College Reading Teaching[J]. Overseas English, 2013.

[11] Sun F. The Application of Schema Theory in Teaching College English Writing[J]. Theory \& Practice in Language Studies, 2014, 4(7).

[12] Pang J P. Students' Expectation and Application of Schema Theory to English Teaching in Vocational Colleges[J]. Overseas English, 2014. 